\title{
Clinically isolated lesions of the type seen in multiple sclerosis: a cognitive, psychiatric, and MRI follow up study
}

\author{
Anthony Feinstein, L D Kartsounis, David H Miller, Bryan D Youl, Maria A Ron
}

\begin{abstract}
There is a dearth of longitudinal studies on psychometric and psychiatric change in multiple sclerosis (MS) particularly on the evolution of these abnormalities early in the disease process. A $4 \frac{1}{2}$ year follow up study documenting magnetic resonance imaging (MRI), psychometric, and psychiatric abnormalities was undertaken in a group of 48 patients with clinically isolated lesions-for example, optic neuritis-which are frequently the harbinger of MS. At follow up about half the subjects had developed clinically definite MS, with memory deficits becoming apparent. Deficits in attention documented at initial assessment were present but unchanged in those subjects who still had a clinically isolated lesion status. However, after MS was categorised into a relapsing-remitting or chronic progressive course, patients with a chronic progressive course were found to have significantly deteriorated with regard to auditory attention tasks. T1 relaxation times in apparently normal white matter correlated with certain indices of cognitive impairment. In developing a model to explain the pathogenesis of intellectual and emotional change in MS, the interaction of organic, psychological, and social factors needs to be emphasised.
\end{abstract}

(F Neurol Neurosurg Psychiatry 1992;55:869-876)

Approximately $50-60 \%$ of patients with multiple sclerosis are estimated to have evidence of cognitive impairment, but little is known about the evolution of these deficits as disease progresses. ${ }^{1}$

The information that exists is often contradictory and methodologically flawed. Longitudinal evidence for ${ }^{2}$ and against ${ }^{34}$ progressive cognitive decline has been reported with considerable individual variation. ${ }^{5}$ Cross sectional studies have either not documented deterioration $^{6}$ or noted it to be mild ${ }^{7}$ and have not contributed to clarifying the problem. What all these studies have in common, however, is a failure to take into account a host of potentially confounding variables - namely, selection bias, whether the course is relapsing-remitting or chronic-progressive, ${ }^{8}$ and clinical exacerbation, ${ }^{9}$ which have all been shown to influence cognition. More equivocal effects such as physical disability ${ }^{10-13}$ and disease duration $^{1415}$ should also ideally be controlled for. When many of these methodological limita- tions were controlled for, ${ }^{16}$ the preliminary evidence after a 1 to 2 year follow up period showed little cognitive deterioration. The only available longer follow up study also suggested that cognitive deterioration had occurred in less than a quarter of patients with multiple sclerosis four years after initial assessment and that there was considerable individual variation. ${ }^{17}$

An analogous position exists with respect to psychiatric disturbance in MS. The high prevalence of affective symptomatology is now well established. ${ }^{18}$ Though there is firm evidence linking the presence of euphoria to cerebral involvement $^{19}$ it is unclear to what extent depressive features can be similarly explained. $^{20}$ The developent and evolution of early psychiatric symptoms and the interplay of organic and social factors in their pathogenesis have yet to be studied.

The study over time of patients with clinically isolated lesions (CIL - namely, optic neuritis and the brain stem and spinal cord syndromes-which are frequently the harbinger of $\mathrm{MS}^{21}$ provides an unique opportunity to monitor cognitive and psychiatric changes early in the disease. Cognitive abnormalities are already discernible in some of these studies at presentation, ${ }^{22}{ }^{23}$ and a follow up of such cases would allow the early natural history to be observed. In addition, the initial paucity of psychiatric symptomatology in subjects with $\mathrm{CIL}^{24}$ offers the opportunity to unravel the various aetiological factors that contribute to greater psychiatric morbidity in those who subsequently develop MS.

In an earlier study, we reported that patients with CIL had significantly greater deficits in auditory and visual attention when compared with a physically disabled control group without brain involvement, matched for age, sex, and premorbid IQ. ${ }^{23}$ The two groups did not, however, differ with respect to psychiatric morbidity. ${ }^{24}$ We present here the results of a follow up study of psychometric, psychiatric, and MRI abnormalities in the above sample of patients who presented initially with clinically isolated lesions of the type seen in MS.

\section{Patients and methods}

\section{Patients}

Forty eight patients with CIL underwent concurrent MRI, and psychometric and psychiatric examination at the National Hospital, Queen Square, London, between 1985 and $1987 .^{23}{ }^{24}$ This group was recalled an average 
of 54 months (range 42 to 67 months) after their original assessment and the above parameters re-examined. The group initially comprised 14 patients with optic neuritis, 16 with a brain stem syndrome, and 18 with a spinal cord syndrome. The sample at follow up was reduced to 44 as the passage of time and reexamination of medical records made it clear that four cases had been incorrectly diagnosed. Thus one patient was rediagnosed as having motor neurone disease and another a presenile dementia of the Alzheimer type. The other two subjects were reassessed as having had MS at the time of inclusion into the study. Of the remaining 44 subjects, $35(80 \%)$ were prepared to return to hospital and undergo the battery of investigations outlined below.

At a single follow up examination the patients were assessed in detail by a neurologist (BDY). A history covering the intervening period was obtained and each patient underwent thorough neurological examination. Present physical disability was rated according to the expanded disability scale (EDSS) ${ }^{25}$ and a note made whether the patient was in exacerbation or not (defined as symptom or symptoms of neurological disturbance, with or without objective confirmation, lasting more than 24 hours). ${ }^{26}$ In addition, hospital case notes and general practitioner records kept during the follow up period were obtained to supplement the above information. On the basis of all information obtained, the Poser criteria $^{26}$ were used to classify the patients clinical status at follow up-that is. CIL or clinically definitive MS. In those who had developed MS the course of the illness was defined as either relapsing-remitting or chronic-progressive. Patients with relapsingremitting disease had experienced a variable number of relapses during the follow up period but the disease remained clinically stable-that is non-progressive-between such episodes. Those with chronic-progressive disease had developed a steady increase in disability for at least six months before follow up and were further divided into a primary and secondary group. The primary group showed a steady decline without remissions since the onset of disease while the secondary group had experienced a relapsing-remitting course before the onset of progression.

\section{Psychometric assessment}

The same cognitive battery used in the initial study was readministered at follow up. The battery comprised seven tests.

Wechsler adult intelligence scale (WAIS) ${ }^{27}$ A shortened version of WAIS giving measures of verbal, performance, and full scale IQs was used. The subtests administered were arithmetic, similarities, digit span, and vocabulary (verbal IQ) and picture completion, picture arrangement, and block design (performance IQ).

Recognition memory tests for words ${ }^{28}$ An age corrected, scaled score based on the number of words correctly recognised was obtained.

Recognition memory test for faces ${ }^{28}$ The same as the preceding test but faces were subsituted for words. Parallel versions of both verbal and visual recognition memory tests were used to minimise practise effects.

Wisconsin card sorting test ${ }^{29}$ A shortened version in which the number of errors was indicative of abstracting ability.

Speed of letter counting ${ }^{30}$ The time taken to count the number of As interspersed with other letters was used as a measure of visual attention.

Auditory attention test ${ }^{23}$ From an auditory presentation, subjects were required to identify in correct order the alphabet embedded in a random collection of letters. The total number of false positives and omissions was taken to present a measure of auditory attention.

Graded naming test ${ }^{31}$ The number of objects correctly named was used as a measure of word retrieval ability.

As research has shown a dissociation between the process of memory retrieval, involving recall and recognition, ${ }^{32}$ we included two additional tests of recall memory to examine this effect in our sample.

Paired-associate learning test ${ }^{33}$ The test material consisted of three groups of 10 pairedassociate noun-verb and three groups of 10 semantically related words. The test stimuli were written on cards and subjects required to read each paired-associate at a rate of one every two seconds. Retention was immediately tested by presenting the first item of each pair (in the same order as in the learning trial), the subject being required to recall the missing item.

Story recall test ${ }^{34}$ Subjects were read a short story and their recall tested immediately after the reading and again after an interval of 30 minutes. Correct, approximate, and incorrect or additional responses were scored as 2,1 , and 0 respectively. Results were age corrected to yield an immediate and delayed recall score. Scores were subdivided into centiles according to published normative data-namely, $<5$ th, 5th-10th, 10th-25th, 25th-50th, 50th-75th, 75 th- 90 th, and $>90$ th and given values of 1 to 7 respectively.

As the paired associate learning test and story recall had not been used in the initial assessment, no comparisons over time could be carried out. Scores from these tests were only used in comparisons between the various subgroups at follow up-that is, CIL, relapsing-remitting disease, or chronic-progressive disease.

An estimate of premorbid IQ had been obtained at the initial interview using the national adult reading test (NART), ${ }^{35}$ and Schonell graded word reading test. ${ }^{36}$ These reading tests have been shown to be resistant to cognitive deterioration and the values obtained at initial assessment were used to determine the decline in IQ by comparing them with the full scale IQ (WAIS) obtained at follow up. This difference was termed the IQ deficit.

Psychometric testing therefore examined the following functions: IQ deficit, verbal and visual recognition memory, verbal recall mem- 
ory, abstracting ability, visual and auditory attention, and naming ability.

\section{Psychiatric assessment}

The clinical interview schedule ${ }^{37}$ (CIS) was used in the initial assessment and was thus repeated to record change in psychiatric status over time. The schedule which includes sections for rating both subjective complaints and objective evidence of psychopathology on a scale of 0 to 4 , measures predominantly neurotic symptoms but has two items for recording psychotic features. Scores greater than or equal to 14 were again taken as the cut off point indicating "caseness." Scores were separately analysed with and without the fatigue item to reduce the influence of physical symptoms on the overall score. To further control for this effect, patients were asked to complete the hospital anxiety and depression scale (HAD), a self rating questionnaire designed specifically to minimise the influence of somatic complaints on the assessment of mood disorders. ${ }^{38}$

To gauge the influence of social factors as perceived by the subject, the social stress and support interview (SSSI) was used. ${ }^{39}$ Scores of 1 for support, 0 if neither support nor stress were evident, and -1 for significant stress were assigned to the following areas; work, finances, housing, social contacts, marriage, and family relationships. High scores therefore represent good support and little social stress with the converse for low scores. The SSSI had been used in the initial study. ${ }^{23}{ }^{24}$

\section{MRI assessment}

All but one subject $(n=34)$, who had a phobia about confined spaces, underwent multislice MRI of the brain (SE/ ${ }_{1500 / 60}$ ) with the same 0.5 Tesla Picker superconducting system used originally. Upgrades to the software during the follow up period had resulted in a reduction of slice thickness from $10 \mathrm{~mm}$ to $5 \mathrm{~mm}$.

The method used to measure the total amount of visible MRI abnormality has been reported elsewhere. ${ }^{40}$ To summarise, the size and presence of lesions were recorded independently by two raters (DHM and AF) in the following periventricular areas: body of the ventricles, frontal, temporal, and occipital horns, trigone; and third and fourth ventricles. In addition eight discrete areas of brain parenchyma were also examined-namely, internal capsule; basal ganglia; frontal, parietal, temporal, and occiptal lobes; brain stem; and cerebellum. In each area the largest lesion was scored according to the longest diameter measured, using a four point scale $(0=1 \mathrm{~mm}$, $1=2-5 \mathrm{~mm}, 2=6-10 \mathrm{~mm}, 3>10 \mathrm{~mm})$. A total lesion score was obtained by adding scores from all the areas and a periventricular score by adding the scores of the periventricular regions.

$T_{1}$ and $T_{2}$ relaxation times, which had not been obtained in the original study, were calculated from algorithms supplied by the manufacturer. A single slice of normal looking frontal white matter was chosen for this purpose using two spin echo (SE/ ${ }_{1500 / 40}$, $\left.\mathrm{SE} /{ }_{1500 / 120}\right)$ and an inversion recovery $\left(\operatorname{IR} /_{1500 / 40 / 500}\right)$ sequence. Analysis was undertaken on a Picker SUN station using the automated programme Analyze. ${ }^{41}$ A manual trace was used to outline the area of frontal white matter, delineating it from cortical grey matter and cerebrospinal fluid. The interface window on the $T_{1}$ weighted images was adjusted to give maximum tissue contrast. The anatomical trace thus obtained was superimposed on the $T_{2}$ weighted image, which had greater sensitivity in showing the presence of MS plaques, and the interface window again adjusted to maximise the contrast between lesion and normal looking white matter. With the additional help of the printed MRI pictures, the lesions (if present) were outined with a manual trace. The aim of the procedure was to define the largest possible area of normal looking frontal white matter, demarcated from cortex and cerebrospinal fluid, from which $T_{1}$ and $T_{2}$ relaxation times were obtained.

Healthy controls $(n=30)$ were scanned over the same period using the above sequences and results of their $T_{1}$ and $T_{2}$ relaxation times compared with those of the subjects. The validity of these measurements were checked using phantoms which controlled for machine drift over time.

All investigations were completed on the same day, in the same order-namely, history and physical examination then MRI, psychometric, and psychiatric assessment. The entire procedure took four hours and was completed before midday in each subject.

Consent was obtained on all patients before taking part in the study.

\section{Statistical analysis}

Both parametric and non-parametric statistics were used depending on whether the data distribution was considered to be normal or not. Thus, in comparing the initial and follow up samples, paired $t$ tests or Wilcoxon matched pairs signed rank tests were used. In the case of non $_{5}$ parametric analysis, the median and range are quoted.

Comparisons between two independent samples were undertaken with two sample $t$ tests and Mann-Whitney $U$ tests. Two tailed $p$ values are reported throughout. One way analysis of variance (ANOVA) and KruskalWallis ANOVA were used in analysing differences between three subgroups, depending on distributions. To reduce the experimental error, only those variables significant at the $5 \%$ level were further analysed with the TukeyKramer multiple comparison method to delineate intergroup differences more clearly. For post-hoc analysis of the significant KruskalWallis tests, Mann-Whitney comparisons were undertaken. Correlations between variables were assessed with either the Pearson's or Spearman rank correlation coefficients.

The software used for the analysis of the data was the statistical package for the social sciences (SPSS). ${ }^{42}$ 
Table 1 Changes in psychometric function over time

\begin{tabular}{lccl}
\hline & $\begin{array}{l}\text { Initial (mean }(S D) \text { or } \\
\text { median (range) }(n=35)\end{array}$ & $\begin{array}{l}\text { Follow up (mean }(S D) \text { or } \\
\text { median (range) }(n=35)\end{array}$ & $\mathrm{p}$ Value \\
\hline IQ deficit & $0 \cdot 0(-11 \cdot 0-14)$ & $0 \cdot 0(-16 \cdot 0-17)$ & $0 \cdot 28$ \\
Naming ability & $22 \cdot 1(4 \cdot 5)$ & $22 \cdot 4(5 \cdot 7)$ & 0.63 \\
Verbal memory & $13(6-15)$ & $13(6-14)$ & 0.92 \\
Visual memory & $11.0(2 \cdot 9)$ & $9 \cdot 1(3 \cdot 9)$ & 0.001 \\
Abstracting ability & $4 \cdot 0(0-17)$ & $4 \cdot 0(0-22)$ & 0.66 \\
Auditory attention & $2 \cdot 0(0-6)$ & $1 \cdot 0(0-10)$ & 0.69 \\
Visual attention & $15 \cdot 6(3.9)$ & $16 \cdot 2(3 \cdot 5)$ & 0.29 \\
\hline
\end{tabular}

\section{Results}

The sample $(\mathrm{n}=35)$ comprised 22 female and 13 male subjects. Nineteen subjects (54\%) had developed clinically definite MS while 16 $(46 \%)$ remained in the isolated lesion category. Among those with isolated lesions of five each $(14 \cdot 3 \%)$ had optic neuritis and brain stem lesions and six $(17 \cdot 1 \%)$ spinal cord syndromes. The 19 subjects with MS were subdivided into $12(34 \cdot 3 \%)$ with a relapsing-remitting (RR) and seven $(20 \%)$ with a chronic-progressive (CP) course. Among those with CP disease, six had a secondary and one a primary progressive course. Of the 19 patients with MS, three were experiencing exacerbations on the day of examination. The mean EDSS for the MS group was 3.5 (range 0 to 8.0 ; median $=3.0$ ). In two patients neurological status precluded the full psychometric battery of tests being completed.

\section{Cognitive change: whole group}

The initial and follow up performance of the whole group ( $\mathrm{n}=35)$ on psychometric testing was compared (table 1). The only function that declined significantly at follow up was visual memory.

\section{Cognitive change: $M S v C I L$}

The follow up group was divided into those with clinically definite $M S$ and those with remaining clinically isolated lesions and the two groups were compared across all parameters. The 19 patients with definite MS did not differ from the 16 subjects with CIL with respect to mean age (40 v 41 years), duration of symptoms (79 $v 76$ months), or age of symptom onset ( $33.6 v 34.8$ years). They were, however, more physically disabled with higher EDSS scores (3.0 $v 1.3 ; p=0.02$ : MannWhitney $U$ ). They also had a significantly higher median lesion score on MRI (19.5 $i$ $2 \cdot 0 ; p=0.0001$ : Mann-Whitney U). No subjects with CIL were taking psychotropic drugs but five with MS were doing so (three benzodiaxepines, two tricyclic antidepressants).

Despite these differences, the MS group performed as well on all psychometric tests except for visual memory, in which their median scores were significantly lower $(10.0 v$ 7.5; $p=0.03$ : Mann-Whitney U).

The differences between MS and CIL were further explored by dividing the MS group into relapsing-remitting $(n=12)$ and chronic-progressive $(n=7)$. The demographic and disease related characteristics of the three groups are shown in table 2 . There were no age differences between the three groups, and though the CP group had a slightly earlier age of symptom onset accounting for an extra year duration of symptoms, this difference was not significant.

However, the CP group was found to differ from the CIL and RR groups on several measures of psychometric testing including story recall (immediate and delayed), paired associated learning, and auditory attention (table 3).

\section{Psychiatric change: entire group}

Psychiatric status based on median CIS scores showed a significant increase in morbidity over time for the group as a whole (median 4.0 $v$ 11.0; $p=0.02$; Wilcoxon matched pairs). Thus, eight subjects had become "cases" at follow up as opposed to one improving to "non-caseness," the rest remaining unchanged ( $\mathrm{p}=0.04:$ McNemar test). Overall, 14 subjects were classed as cases.

Analysis of the CIS without the fatigue item still showed a significant difference between the initial and follow up scores $(4.0 v 10.0$; $\mathrm{p}=0.05:$ Wilcoxon matched pairs). However, when change in caseness over time was reanalysed with fatigue removed from the scoring, the significance was no longer apparent, five patients becoming cases and one improving to non-caseness ( $p=0.22 ; \mathrm{McNemar}$ test).

Analysis of individual items on the CIS showed that preoccupation with physical complaints, such as fatigue, and concentration difficulties were significantly more common at follow up ( $p=0.05$ for all; Wilcoxon matched pairs) with a trend for depressive and obsessive symptoms to be more prevalent ( $p=0.06$ for both).

No subjects were psychotic at follow up, although in the interim one had been admitted to hospital with a paranoid psychosis that

Table 2 Age and disease characteristics for the clinically isolated lesion, relapsing-remitting, and chronic-progressive MS groups

\begin{tabular}{|c|c|c|c|c|c|c|c|}
\hline & $\begin{array}{l}C I L \text { (mean }(S D) \text { or } \\
\text { median (range)) }(n=16)\end{array}$ & $\begin{array}{l}R R(\text { mean }(S D) \text { or } \\
\text { median (range)) }(n=12)\end{array}$ & $\begin{array}{l}C P(\text { mean }(S D) \text { or } \\
\text { median }(\text { range) })(n=7)\end{array}$ & p Value & $1 \mathrm{v} 2$ & $2 v 3$ & $1 \mathrm{v} 3$ \\
\hline $\begin{array}{l}\text { Age } \\
\text { Sex (M:F) } \\
\text { Education } \\
\text { Age at symptom onset (years) } \\
\text { Duration of symptoms (months) } \\
\text { Duration of follow up (months) } \\
\text { Kurtzke's EDSS } \\
\text { Total MRI lesion score }\end{array}$ & $\begin{array}{l}41 \cdot 3(10 \cdot 6) \\
6: 10 \\
12 \cdot 3(1 \cdot 4) \\
34 \cdot 8(10 \cdot 9) \\
76 \cdot 3(39 \cdot 9) \\
55 \cdot 5(6 \cdot 7) \\
1 \cdot 35(0-4 \cdot 5) \\
2 \cdot 0(0-24)\end{array}$ & $\begin{array}{l}39 \cdot 8(11 \cdot 8) \\
3: 9 \\
11 \cdot 6(1 \cdot 4) \\
34 \cdot 1(10 \cdot 9) \\
71 \cdot 8(38 \cdot 1) \\
51 \cdot 6(7 \cdot 7) \\
2 \cdot 3(0-6) \\
18 \cdot 5(4-36)\end{array}$ & $\begin{aligned} & 40.4(13 \cdot 8) \\
& 4: 3 \\
& 11.9(1 \cdot 5) \\
& 32.9(13 \cdot 1) \\
& 90.9(25 \cdot 8) \\
& 55 \cdot 1(6 \cdot 3) \\
& 4.5(1-8) \\
& 23.5(14-47)\end{aligned}$ & $\begin{array}{l}0.94 \\
0.46 \\
0.93 \\
0.55 \\
0.45 \\
0.01 \\
0.0001\end{array}$ & $\begin{array}{l}\cdot \\
\dot{5} \\
\dot{5} \\
\dot{.}\end{array}$ & $\dot{.}$. & $\begin{array}{l}\cdot \\
\dot{b} \\
\dot{ } \\
\vdots \\
\star\end{array}$ \\
\hline $\begin{array}{l}\text { Relaxation times: } \\
\text { T1 } \\
\text { T2 }\end{array}$ & $\begin{array}{c}425 \cdot 9(15 \cdot 4) \\
78 \cdot 0(3 \cdot 1)\end{array}$ & $\begin{array}{c}431 \cdot 3(15 \cdot 9) \\
78 \cdot 8(2 \cdot 7)\end{array}$ & $\begin{array}{c}440.9(28 \cdot 6) \\
80.6(6 \cdot 6)\end{array}$ & $\begin{array}{l}0 \cdot 28 \\
0 \cdot 41\end{array}$ & . & 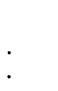 & $\dot{ }$ \\
\hline
\end{tabular}


Table 3 Results of the psychometric and psychiatric performance of the isolated lesion, relapsing-remitting, and chronic-progressive groups

\begin{tabular}{|c|c|c|c|c|c|c|c|}
\hline & \multirow[b]{2}{*}{$\begin{array}{l}C I L(\text { mean }(S D) \text { or } \\
\text { median }(\text { range })(n=16)\end{array}$} & \multirow[b]{2}{*}{$\begin{array}{l}R R(\text { mean }(S D) \text { or } \\
\text { median (range)) }(n=12)\end{array}$} & \multirow[b]{2}{*}{$\begin{array}{l}C P(\text { mean }(S D) \text { or } \\
\text { median (range)) }(n=7)\end{array}$} & \multirow[b]{2}{*}{ p Value } & \multicolumn{3}{|c|}{ post-hoc Tukey } \\
\hline & & & & & $1 \mathrm{v} 2$ & $2 \mathrm{v} 3$ & $1 \mathrm{v3}$ \\
\hline NART & $112 \cdot 1(7 \cdot 5)$ & $112 \cdot 4(5 \cdot 0)$ & $106 \cdot 1(8 \cdot 2)$ & $0 \cdot 12$ & . & . & . \\
\hline Full IQ [WAIS) & $113 \cdot 1(12.4)$ & $113.0(8.6)$ & $102 \cdot 8(11 \cdot 2)$ & $0 \cdot 17$ & . & . & . \\
\hline IQ deficit & $-0.93(8.1)$ & $-0.67(6.6)$ & $3.8(7.7)$ & $0 \cdot 46$ & . & . & . \\
\hline GNT & $23.5(4.8)$ & $21.8(6.8)$ & $21.0(6.4)$ & 0.59 & . & : & . \\
\hline Verbal memory & $13.0(8-14)$ & $13 \cdot 0(6-14)$ & $11 \cdot 0(8-14)$ & $0 \cdot 36$ & . & : & . \\
\hline Visual memory & $10 \cdot 6(4 \cdot 0)$ & $7 \cdot 6(3 \cdot 2)$ & $8 \cdot 0(4 \cdot 0)$ & 0.09 & . & . & . \\
\hline \multirow{2}{*}{$\begin{array}{l}\text { Story recall: } \\
\text { Immediate } \\
\text { Delayed }\end{array}$} & & & & & & & \\
\hline & $\begin{array}{l}4.4(1.5) \\
4.6(1.5)\end{array}$ & $\begin{array}{l}4.5(1.2) \\
4.5(1.2)\end{array}$ & $\begin{array}{l}2.7(1 \cdot 3) \\
2 \cdot 9(1 \cdot 3)\end{array}$ & $\begin{array}{l}0.02 \\
0.02\end{array}$ & $\therefore$ & * & ^ \\
\hline \multicolumn{8}{|l|}{ PALT: } \\
\hline Semantic & $25 \cdot 8(4 \cdot 0)$ & $26.5(3.5)$ & $23.5(3.4)$ & 0.29 & . & & \\
\hline Noun-verb & $25 \cdot 4(3 \cdot 2)$ & $24 \cdot 1(4 \cdot 7)$ & $18 \cdot 3(4 \cdot 2)$ & 0.003 & . & * & * \\
\hline Abstracting & $5 \cdot 2(5 \cdot 1)$ & $5 \cdot 0(5 \cdot 6)$ & $5 \cdot 2(4 \cdot 3)$ & 0.99 & . & & \\
\hline Auditory attention & $1.0(0-6)$ & $0.5(0-3)$ & $3 \cdot 5(0-10)$ & 0.05 & . & * & $\star$ \\
\hline Visual attention & $15.7(2.8)$ & $15.6(3.5)$ & $19.5(4 \cdot 5)$ & 0.08 & . & . & . \\
\hline CIS & $8 \cdot 4(7 \cdot 6)$ & $10.7(9 \cdot 1)$ & $16.0(9 \cdot 3)$ & $0 \cdot 16$ & . & . & . \\
\hline \multicolumn{8}{|l|}{ HAD: } \\
\hline Full HAD & $8 \cdot 9(6 \cdot 1)$ & $10.0(6.5)$ & $15 \cdot 3(7 \cdot 3)$ & 0.1 & . & . & . \\
\hline Anxiety & $5 \cdot 3(3 \cdot 8)$ & $6.5(4 \cdot 1)$ & $6.0(3.8)$ & 0.72 & . & i & i \\
\hline Depression & $3 \cdot 7(3 \cdot 1)$ & $3.5(3.3)$ & $9.3(4.9)$ & 0.003 & . & * & $\star$ \\
\hline SSSI & $5 \cdot 0(1-6)$ & $3 \cdot 0(0-6)$ & $2.5(0-6)$ & $0 \cdot 04$ & . & & ^ \\
\hline
\end{tabular}

GNT = graded naming test; PALT = paired associate learning test; CIS = clinical interview schedule; HAD = hospital anxiety and depression scale; SSSI = social stress and support interview.

${ }^{\star} \mathrm{p}<0.05$.

lasted 10 days and responded well to chlorpromazine. Euphoria had developed in two subjects, both markedly disabled and with a chronic-progressive disease course.

Psychiatric change: clinically isolated lesion $v$ MS

There was a trend for the MS group to have higher CIS scores (7.5 v 11.0; $\mathrm{p}=0.09$; Mann-Whitney U) than did those with CIL, but they were equally likely to be classed as cases. This non-significant trend was also present for the HAD scale, with the MS group having higher mean scores for anxiety (5.3v $6.3 ; \mathrm{p}=0.45)$ and depression (3.7 v 5.6; $\mathrm{p}=0 \cdot 16$ ).

More marked differences became apparent when the MS group was subdivided into relapsing-remitting and chronic-progressive. The CP subgroup had scores on the clinical interview schedule double those of the CIL subgroup, and while all three subgroups had similar results on the HAD anxiety scale, the CP group's HAD depression ratings were three times those of the two others (table 3 ).

\section{Change in social stress and support}

For the group as a whole scores on the SSSI did not show a deteroration over time-that is, subjects did not perceive themselves to be under more stress or receiving less support (3.8 $v$ 3.6; $\mathrm{p}=0.79$ : Wilcoxon matched pairs). However, when the group was split into CIL and MS, the latter were experiencing greater social stress $(4.4 v 3.0 ; \mathrm{p}=0.05$; Mann-Whitney U). Further subdivision of the MS group into RR and CP illustrated significant differences between the CIL and CP subgroups (table 3 ). The SSSI correlated significantly with the degree of physical disability ( $r=-0.42 ; p=0.01$ : Spearman's rank).

Interaction of cognition, psychiatric, and social variables

To investigate the possible confounding effects of psychiatric and social variables on sig- nificant differences in cognition between the CIL, RR, and CP groups, analyses of covariance were performed on the four cognitive variables where ANOVA had shown subgroup differences. Thus, story recall (immediate and delayed), PALT (noun-verb), and auditory attention were entered as the dependent variables and social stress and support, physical disability, and psychiatric state as the covariates. This removed the significant differences between the groups with respect to recall memory tests, although trends remained for all three. Significant differences persisted, however, for the auditory attention task $(p=0.04)$. The majority of the variance was accounted for by a combination of psychiatric state and social stress, psychiatric state having a slighter greater influence.

With regard to psychiatric measures, differences in depression scores on the HAD between the three subgroups were reanalysed with social stress and support, physical disability, and sex as the covariates. Significant differences between the three subgroups were no longer apparent. Most of the variance was accounted for by the social stress variable, with the remaining two having a negligible influence.

An attempt was made retrospectively to identify features that may have predicted a chronic-progressive or relapsing-remitting course at the initial examination. The seven patients with CP (three of whom presented with spinal cord syndromes, three with brain stem syndromes, and one with optic neuritis) did not differ from the RR or CIL groups in terms of demographic, psychometric, or psychiatric variables, although they already had a significantly higher MRI lesion score than the rest of the group at the initial assessment (14.0 $v 5 \cdot 0 ; \mathrm{p}=0.02$ : Mann-Whitney $U$ ).

\section{MRI follow up}

Only four patients had normal scans at follow up, as opposed to eight in the initial study. Comparisons between the initial and follow up 
MRI scans were not possible because of differences in slice thickness. At the follow up assessment differences in total lesion score between the three groups were apparent, the subjects with CIL differing from both the RR and CP groups respectively (table 2 ).

Using the quantitative lesion score, no significant correlations were found with psychiatric status. Of the individual functions, visual (recognition) memory alone was significantly related to MRI total lesion score $(\mathrm{r}-0.47 ; \quad \mathrm{p}=0.01$ : Pearson's productmoment correlation coefficient).

Although the $\mathrm{T} 1$ and $\mathrm{T} 2$ relaxation times of the patients were higher than those of the controls, this difference was not significant (mean T1: $430.2 v 425.4$; mean T2: $78.6 v$ 77.5 respectively). When the CIL values were excluded and only the definite MS compared with normal controls, a trend was observed for higher T1 values in the MS group (mean 434.3 $v 421.9 ; \mathrm{p}=0.06)$. T1 values correlated with total lesion score $(r=0.51 ; p=0.01$ : Spearman's rank correlation coefficient).

Significant correlations were also found between raised $T 1$ relaxation times and naming ability ( $r=-0.43 ; p=0.01$ : Pearson's correlation coefficient), abstracting ability $(\mathrm{r}=0.43 ; \quad \mathrm{p}=0.01 ;$ Spearman's rank correlation coefficient), and visual memory $(r=-0.50 ; p=0.01$ : Spearman's rank correlation coefficient).

\section{Discussion}

The results of a follow up study on 35 subjects with clinically isolated lesions of the type seen in MS are reported. In the initial study the CIL group was found to be significantly more cognitively but not psychiatrically impaired than a group of physically disabled controls matched for age, sex, and premorbid IQ. After a $4 \frac{1}{2}$ year follow up approximately half the sample had developed clinically definite MS, a rate in agreement with previous reports. ${ }^{214344}$ As a group, an increase in psychiatric morbidity was apparent (CIS scores, but not caseness) and performance in tests of visual memory had deteriorated. When subdivided according to disease course, those with a chronic-progressive pattern were found to have further deteriorated on tests of auditory attention.

While longitudinal studies are necessary to determine the natural history of cognitive decline, they are in turn bedevilled by the difficulties of controlling for practice effects. In this study the use of parallel forms of memory tests and the long period that elapsed between the two examinations are likely to have minimised practice effects. The possibility nevertheless remains that the extent of cognitive decline may have been slightly underestimated by our design, but this could not account for the differences between the various subgroups emerging at follow up.

Memory impairment has often been described in patients with definite $\mathrm{MS},{ }^{45}$ and indirect evidence from cross sectional studies suggest that memory functions deteriorate over time. ${ }^{4647}$ The only available follow up study on patients with MS suggests considerable individual variation in memory deterioration after an interval of four years. ${ }^{17}$ Our study confirms that finding and documents the natural history of cognitive deficits from the time the first neurological manifestations of the disease (CIL) occurred. Our longitudinal data show visual memory to be more vulnerable to advancing disease than other types of memory.

There was a large degree of overlap in cognitive performance between the CIL and RR groups, even though patients with relapsing-remitting disease are more physically disabled. One possible explanation could be that only one of the 12 subjects with relapsingremitting MS was in exacerbation, which has been shown to have an adverse effect on cognition. ${ }^{914}$ Although these results confirm the presence of cognitive impairment in patients with relapsing-remitting MS noted by previous authors, ${ }^{49}$ these deficits seem to remain relatively mild and constant over time provided the disease remains in remission.

The MRI, psychometric, and psychiatric abnormalities were consistently more severe in the CP compared with the CIL and RR groups, although they reached significance with respect only to auditory attention and MRI lesion score. The failure to demonstrate more widespread impairment in our CP subgroup may represent a type II error given the small number of patients with $\mathrm{CP}$ disease. Nevertheless, their performance is broadly in keeping with results from other studies ${ }^{850}$ and suggests that in definite MS disease type is a more sensitive marker of cognitive decline than either disability or duration, variables found to be unrelated to cognitive impairment in our sample. Cognitive impairment thus seems to be related directly to more severe degrees of brain pathology, which in turn results in greater physical disability in this group. The correlations of cognition with duration of illness $^{14}$ and physical disability ${ }^{12}$ reported by others in advanced disease may have obscured a more fundamental relation between cognitive impairment and course of MS.

Though as a group patients with CP disease had more impaired cognitive performance, their scores were not homogeneous and a degree of individual variability was present. A division of subjects with CP primary and secondary has been recommended on the grounds that they differ widely with respect to brain imaging. ${ }^{51}$ However, the small number of such patients in our sample did not allow us to determine whether cognitive impairment was less marked in those with a primary progressive course in whom MRI abnormalities were also less severe.

The only significant correlation between total MRI lesion score and a cognitive variable was with visual memory. In finding only a single correlation, our results are comparable with those of Franklin et al, who used a similar procedure in assessing lesion involvement on MRI, ${ }^{52}$ but they differ from those of others who found an association between total lesion 
area and a large number of cognitive variables. ${ }^{53}$ Differences in methods of estimating lesion volume are likely to account for this discrepancy and the use of more precise quantitative methods may reveal significant correlations in future studies.

Our study is, to our knowledge, the first to describe a significant correlation between white matter relaxation times and focal cognitive deficits. Such associations have been reported in Alzheimer's disease, ${ }^{54}$ but not to date in MS. An increase in T1 relaxation times reflect the presence of microscopic abnormalities (perivascular inflammation, myelin breakdown, and astrocyte hyperplasia ${ }^{55}$ ) in the MRI normal looking white matter and are likely to be sensitive indicators of the presence of brain pathology responsible for the detectable cognitive impairment.

The assessment of psychiatric morbidity in physically ill patients is not without problems as it is difficult to separate somatic symptoms - for example, fatigue - that occurred in the context of a physical disease from those which are an integral part of depression. Notwithstanding this, it is important to apply standard psychiatric instruments to these patients if their psychiatric phenomenology is to be understood. In a previous study the CIS proved able to distinguish psychiatric symptoms in patients with MS from those directly attributable to their physical disability by comparing their results with those of a matched control group, also physically disabled, but without brain involvement. ${ }^{56}$ In the present study these confonding effects have been minimised by excluding fatigue, a common MS symptom, and by using a self report questionnaire (HAD) designed specifically for use in a hospital population and therefore less reliant on physical symptoms.

When our patients were first examined over four years ago they had a low prevalence of psychiatric morbidity, not greater than that encountered in the general population. ${ }^{24}$ However, at follow up $40 \%$ had become psychiatric cases, a figure higher than that found (for subjects without MS) in community samples ${ }^{57}$ or in general practice attenders. ${ }^{58}$ However, when the effects of fatigue were removed from the analysis, the change in caseness over time was not significant, although the percentage still exceeded that for community and general practice attenders. In addition, CIS scores (even with fatigue excluded from the follow up) showed a significant increase over time. This increase in psychiatric morbidity was further confirmed by the high depression scores in the CP group on the HAD scale.

Observing the phenomenology of psychiatric change more closely, somatic complaints including fatigue, concentration difficulties, and obsessional thoughts were the commonly endorsed items, and as previously reported ${ }^{18}$ the typical picture of depression associated with social withdrawal and guilty ruminations was rarely encountered. Euphoria was rare in our sample and confined to two subjects, both of whom had a CP course and were severely physically disabled. This supports the view that euphoria is closely associated with the severity of brain pathology. ${ }^{59}$ The degree of physical disability was not related to psychiatric morbidity but correlated well with the degree of perceived social stress and support; when the effect of this variable was controlled for, differences in depression between the three subgroups disappeared. The subjective perception of stress and support (SSSI) measured in our study is likely to be coloured by the presence of depressed mood and therefore not wholly independent of other psychiatric ratings. However, the many adverse changes experienced by these patients as their disability progresses, also reflected in this index, have a clear role in the pathogenesis of psychiatric morbidity. ${ }^{56}$

This study has been the first to illustrate how cognitive and psychiatric morbidity evolves as disease progresses from clinically isolated lesion status to definite MS. It has highlighted the central role of brain pathology and the related variable disease course, in determining the extent and rate of progression of cognitive disability. It has also confirmed the early development of memory deficits and emphasised the lack of close correlation between psychiatric morbidity and extent of measurable brain pathology.

The research was carried out at the Institute of Neurology and the National Hospital for Neurology and Neurosurgery, Queen Square, London WCIN 3BG, and was funded by the Wellcome Trust. Dr Ron was partially supported by the Scarfe Trust. We thank the MS society of Great Britain/Northern Ireland for generous access to the NMR scan. We would also like to acknowledge David MacManus and Sue Moore for the MRIs, Drs Dave Wicks and Ian Harvey for advice on image analysis,
Peter Sacares for statistical help, Drs Logsdail and Callanan for data from the original study, and Professors McDonald and Warrington for their helpful comments. The assistance of the patients is also gratefully recognised.

1 Peyser JM, Rao SM, LaRocca NG, Kaplan E. Guidelines for neuropsychological research in multiple sclerosis. Arch Neurol 1990;47:94-7.

2 Canter AH. Direct and indirect measures of psychological deficit in multiple sclerosis. $\mathcal{F}$ Gen Psychol 1951;44:3-50.

3 Fink SL, Houser HB. An investigation of physical and intellectual changes in multiple sclerosis. Arch Phys Med Rehabil 1966;47:56-61.

4 Ivnik RJ. Neuropsychological stability in multiple sclerosis. fournal of Consulting and Clinical Psychology
1978;46:913-23.

5 Young AC, Saunders J, Ponsford JR. Mental change as an early feature of multiple sclerosis. $\mathcal{f}$ Neurol Neurosurg Psychiatry 1976;39:1008-13.

6 Ivnik RJ. Neuropsychological test performance as a function of the duration of MS-related symptomatology. $\boldsymbol{f}$ Clin Psychiatry 1978;April;304-12.

7 Halligan FR, Reznikoff M, Friedman HP, LaRocca NG Cognitive dysfunction and change in multiple sclerosis. $\mathcal{J}$ Clin Psychol 1988;44:540-8.

8 Heaton RK, Nelson LM, Thompson DS, Burks JS, Franklin GM. Neuropsychological findings in Relapsing-Remitting and Chronic-Progressive Multiple Sclerosis. fournal of Consulting and Clinical Psychology 1985;53:103-10.

9 Bieliauskas LA, Topel JL, Huckman MS. Cognitive, neurologic and radiologic test data in a changing lesion pattern. fournal of Clinical Neuropsychology 1980;2:217-300.

10 Huber SJ, Paulsen GW, Shuttleworth EC, et al. Magnetic resonance imaging correlates of dementia in multiple relerosis. Arch Neurol 1987;44:732-6.

11 Stenager E, Knudsen L, Jensen K. Correlation of Beck depression inventory score, Kurtzke disability status and cognitive functioning in multiple sclerosis. In: Jensen $K$, Knudsen L, Stenager E, Grant I, eds. Current problems in neurology: 10. Mental disorders and cognitive deficits in neurology: 10. Mental disorders and cognitive deficits in
multiple sclerosis. London: John Libbey, 1989:147-52.

12 Marsh GG. Disability and intellectual function in multiple sclerosis patients. $\mathcal{F}$ Nerv Ment Dis 1980;168:758-62.

13 Franklin GM, Heaton RK, Nelson LM, Filley CM, Seibert C. Correlations of neuropsychological and MRI findings in chronic/progressive multiple sclerosis. Neurology 1988;38:1826-9.

14 Grant I, McDonald WI, Trimble MR, Smith E, Reed R. Deficient learning and memory in early and middle 
phases of Multiple Sclerosis. $\mathcal{F}$ Neurol Neurosurg Psychiatry 1984;47:250-5.

15 Rao SM, Hammeke TA, McQuillen MP, Khatri BO, Lloyd D. Memory disturbance on chronic-progressive multiple sclerosis. Arch Neurol 1984;41:625-31

16 Filley CM, Heaton RK, Thompson LL, Nelson LM, Franklin GM. Effects of disease course on neuropsychological functioning. In: Rao SM, ed. Neurobehavioural aspects of multiple sclerosis. New York: Oxford University aspects of multiple scleros
Press, 1990:136-48.

17 Jennekens-Schinkel A, Laboyrie PM, Lanser JBK, van der Velde EA. Cognition in patients with multiple sclerosis
Vel after four years. I Neurol Sci 1990;99:229-47.

18 Minden SL, Orav J, Reich P. Depression in multiple sclerosis. Gen Hosp Psychiatry 1987;9:426-34.

19 Rabins PV, Brooks BR, O'Donnell P, et al. Structural brain correlates of emotional disorder in multiple sclerosis. Brain 1986;109:585-97.

20 Minden S, Schiffer RB. Affective disorders in multiple sclerosis. Arch Neurol 1990;47:98-104.

21 Francis DA, Compston DAS, Batchelor JR, McDonald WI. A reassessment of the risk of multiple sclerosis developing in patients with optic neuritis after extended follow-up. $尹$ Neurol Neurosurg Psycchiatry 1987;50:758-65.

22 Lyon-Caen O, Jouvent $\mathrm{R}$, Hauser $\mathrm{S}$, et al. Cognitive function in recent onset demyelinating diseases. Arch Neurol 1986;43:1138-41.

23 Callanan MM, Logsdail SJ, Ron MA, Warrington EK Cognitive impairment in patients with clinically isolated lesions of the type seen in multiple sclerosis. Brain 1989;112:361-74.

24 Logsdail SJ, Callanan MM, Ron MA. Psychiatric morbidity in patients with clinically isolated lesions of the type seen in multiple sclerosis: a clinical and MRI study. Psycho Med 1988;18:355-64.

25 Kurtze JF. Rating neurologic impairment in multiple sclerosis: an expanded disability scale. Neurology 1983;33: 1444-42.

26 Poser CM, Paty DW, Scheinberg L, et al. New diagnostic criteria for multiple sclerosis: guidelines for research criteria for multiple sclerosis: guidel

27 Wechsler D. Wechsler adult intelligence scale: manual. New York: Psychological Corporation, 1955.

28 Warrington EK. Recognition memory test. Windsor: NFERWarrington EK.

29 Nelson HE. A modified card sorting test sensitive to frontal lobe defects. Cortex 1976;12:313-24.

30 Willison JR, Thomas DJ, du Boulay, et al. Effect of high haematocrit on alertness. Lancet 1980;i:846-8.

31 McKenna P, Warrington EK. Graded naming test: manual. Windsor: NFER-Nelson, 1983.

32 Delbecq-Derouesne J, Beauvois MF, Shallice T. Preserved recall versus impaired recognition: a case study. Brain 1990;113:1045-74.

33 Warrington EK, Weiskrantz L. Amnesia: a disconnection syndrome? Neuropsychologia 1982;20:233-48.

34 Caughlan AK, Hollows SE. The adult memory and information processing battery. Leeds, 1985 .

35 Nelson HE. National adult reading test: manual. Windsor: NFER-Nelson, 1982.

36 Nelson HE, O'Connell FJ. Dementia: estimation of premorbid intelligence levels using the New Adult Reading Test. Cortex 1978;14:234-44.

37 Goldberg DP, Cooper B, Eastwood MR, Kedward HB, Shepherd M. A standardised psychiatric interview for use in community surveys. British Fournal of Preventative and Social Medicine 1974;24:18-23.

38 Zigmond AS, Snaith RP. The hospital anxiety and depression scale. Acta Psychiatrica Scand 1983;67:361-70.

39 Jenkins R, Mann AH, Belsey E. Design and use of a shor interview to assess social stress and support in research and clinical settings.Soc Sci Med 1981;151:195-203.

40 Ormerod IEC, Miller DH, McDonald WI, et al. The role of NMR imaging in the assessment of multiple sclerosis and isolated neurological lesions: a quantitative study. Brain 1987;110:1579-616.

41 Biodynamics Research Unit: Mayo Foundation. Analyze user's manual, version 3.0 Rochester, Minnesota: Mayo Clinic, 1986.

42 Norusis MJ. SPSS/PC ${ }{ }_{T M}$ for the IBM/PC/XT/AT. Chicago: SPSS, 1989.

43 Bradley WG, Whitty CWM. Acute optic neuritis: prognosis for development of multiple sclerosis. $\mathcal{F}$ Neurol Neurosurg Psychiatry 1968;31:10-18.

44 Miller DH, Ormerod IEC, Rudge P, Kendall BE, Moseley IF, McDonald WI. The early risk of multiple sclerosis following isolated acute syndromes of the brain stem and spinal cord. Ann Neurol 1989;26:635-9.

45 Litvan I, Grafman J, Vendrell P, et al. Multiple memory deficits in patients with multiple sclerosis. Exploring the working memory system. Arch Neurol 1988;45:607-10.

46 Van den Burg W, van Zomeren AH, Minderhoud JM, Prange AJM, Meijer NSA. Cognitive impairment in patients with multiple sclerosis and mild physical dispatients with multiple sclerosis and

47 Ron MA, Calanan MM, Warrington EK. Cognitive abnormalities in multile sclerosis: a psychometric and MRI malities in multile sclerosis: a psych
study. Psychol Med 1991;21:59-68.

48 Beatty WW, Goodkin DE, Monson MN, Beatty PA Cognitive disturbance in patients with relapsing-remitting multple sclerosis. Arch Neurol 1989;46:1113-9.

49 Anzola GP, Bevilacqua L, Capra R, et al. Neuropsychological assessment in patients with relapsing-remitting multiple sclerosis and mild functional impairment: correlation with magnetic resonance imaging. $\mathcal{F} \mathrm{Neurol} \mathrm{Neu}$ rosurg Psychiatry 1990;53:142-5.

50 Rao SM, Hammeke TA, Speech TJ. Wisconsin Card Sort Test performance in relapsing-remitting and chronicprogressive multiple sclerosis. fournal of Consulting and progressive multiple sclerosis. Fournal

51 Thompson AJ, Kermode AG, Wicks D, et al. Major differences in the dynamics of primary and secondary progressive multiple sclerosis. Ann Neurol 1991, 29:53-62.

52 Franklin GM, Heaton RK, Nelson LM, Filley CM, Seibert C. Correlation of neuropsychological and MRI findings in chronic-progressive multiple sclerosis. Neurology 1988;38:1826-29.

53 Rao SM, Leo GJ, Haughton VM, St Aubin-Faubert P, Bernardin L. Correlation of magnetic resonance imaging with neuropsychological testing in multiple sclerosis. Neurology 1989;39:161-6.

54 Besson JAO, Crawford JR, Parker DM, et al. Multimodal imaging in Alzheimer's disease. The relationship between Psychiatry 1989;127:216-20.

55 Allen IV, Glover G, Andersen R. Abnormalities in the macroscopically normal white matter in cases of mild or spinal multiple sclerosis. Acta Neuropathol (Berl) 1981:(suppl 7):176-8.

56 Ron MA, Logsdail SJ. Psychiatric morbidity in multiple sclerosis: a clinical and MRI study. Psychol Med 1989;19:887-95.

57 Andrews G, Schonell $M$, Tennent $C$. The relationship between physical, psychological and social morbidity in a suburban community. Am $\mathcal{F}$ Epidemiol 1977;105:324-9.

58 Goldberg DP, Blackwell BB. Psychiatric illness in general practice. A detailed study using a new method of case identification. $B M \mathcal{F}$ 1970;ii:439-43.

59 Rabins PV. Euphoria in multiple sclerosis. In: Rao SM, eds. Neurobehavioural aspects of multiple sclerosis. New York: Neurobehavioural aspects of multiple scler
Oxford University Press, 1990:180-5. 